Netzwerk nichts mehr zu erwarten haben. Wir sind jetzt die Altvorderen, wir sind der Ansporn für die Jungen.

Letzte Woche war ich bei einer anderen meiner „Wahlmütter“, der 91-jährigen früheren Rechtsanwältin Dr. Alice Haidinger, die mit einem Jahr Unterbrechung seit 1954, also seit mehr als 50 Jahren, im djb Karlsruhe ist. Sie hat bisher keine Ehrennadel erhalten; aber sie gönnt mir meine. Hier zeigen sich Unterschiede zwischen den Ortsgruppen. Wie Ursula Nelles vor ein paar Monaten anlässlich der Veranstaltung zu zehn Jahre Umzug der Geschäftsstelle nach Berlin gesagt hat: „Der Schwerpunkt ist jetzt eindeutig Berlin. Die Berliner Stärke des djb schwächt indessen die Aktivitäten in der Fläche.“
Vielleicht sollten wir dazu aufrufen, dass meine Generation und die noch Älteren gefunden werden, damit sie Gelegenheit haben, ihre Erfahrungen in der Fläche einzubringen. Die Jungen machen die Arbeit und ich bin froh darüber. Aber manchmal - wie heute - hilft auch Zuhören weiter. Nicht alles muss neu erfunden werden.

Und neben der Erfahrung haben wir Seniorinnen einiges zu bieten: Gedächtnis und Zähigkeit verbunden mit Optimismus.

Ich schließe mit einer Bemerkung, die ich schon oft gemacht habe:

Wir spüren den Fortschritt nicht, solange wir im Strom der Zeit schwimmen. Aber im Rückblick beglückt uns das dennoch Erreichte.

\title{
Landesverband Saarland fordert „Parité-Gesetz“
}

Während sich das deutsche Wahlvolk aus 51,5 Prozent Frauen und 48,5 Prozent Männern zusammensetzt, bestimmen im Bundestag nur 33 Prozent Frauen, aber 67 Prozent Männer die Politik. In den Landtagen und Kommunalparlamenten ist bundesweit das Übergewicht der männlichen Abgeordneten sogar noch größer. Diese mangelnde paritätische Besetzung der Parlamente begünstigt natürlich politische Entscheidungen und Gesetze, welche an den Interessen von Frauen vorbeigehen. Ein Parité-Gesetz, wie es in mehreren europäischen Ländern schon existiert, würde nun die politischen Parteien verpflichten, ihre Wahllisten nach dem Reißverschlussprinzip paritätisch mit Frauen und Männern zu besetzen - mit der Folge, dass in den Parlamenten Frauen und Männer gleichmäßig repräsentiert wären.

Die Forderung nach der Einführung eines solchen ParitéGesetzes hat sich der djb-Landesverband Saarland seit letztem Dezember auf die Fahnen geschrieben, und zwar im Anschluss an den Festvortrag, den Prof. Dr. Silke Ruth Laskowski (Kassel) im Rahmen der letzten Weihnachtsveranstaltung in Saarbrücken gehalten hatte.

In Kooperation mit dem Frauenbüro Saarbrücken und dem saarländischen Frauenrat lud der djb-LV Saarland daher jetzt saarlandweit für den 1. Oktober 2012 in den Landtag ein, wo Prof. Dr. Laskowski den über 100 Anwesenden in einem überzeugenden und mitreißenden Vortrag darlegte, dass ein Paritégesetz nicht nur mit dem Grundgesetz vereinbar, sondern sogar verfassungsrechtlich geboten ist - wenn wir das Demokratiekonzept der Volkssouveränität im Grundgesetz

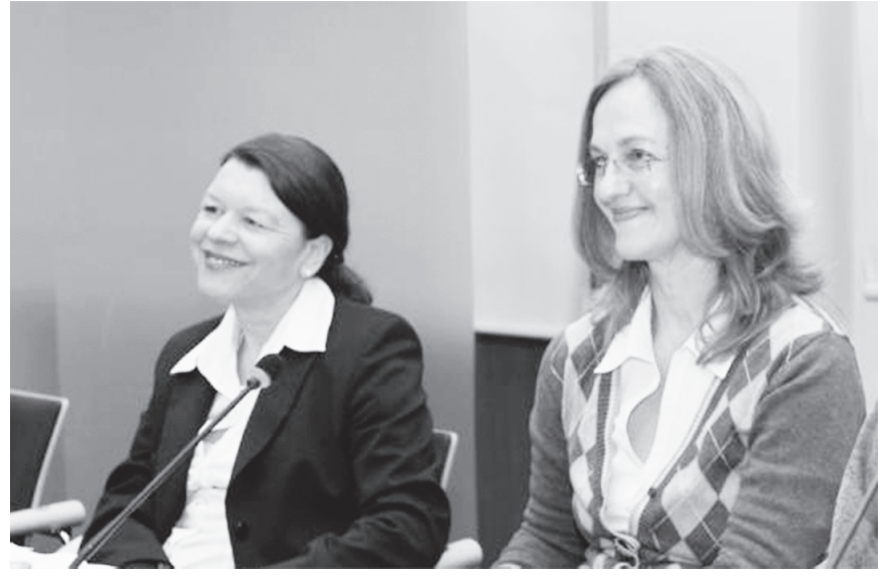

A Prof. Dr. Silke Ruth Laskowski, Universität Kassel (links), spricht über „Demokratie und Gleichberechtigung - warum mehr Frauen in die Parlamente gehören!“

ernst nehmen. Eine gleichberechtigte demokratische Teilhabe von Frauen und Männern nach Artikel 20 Absatz 2 Satz 2, Artikel 21 Absatz 1 Satz 3, Artikel 3 Absatz 2 Satz 1 und 2 GG wird anders nicht durchsetzbar sein.

Im Anschluss diskutierten unter der Moderation von Prof. Dr. Heide Pfarr die frauenpolitischen Sprecherinnen der fünf im Saarländischen Landtag vertretenen Fraktionen. Am Ende des Abends waren sich die Politikerinnen weitgehend einig, dass sie den Vorstoß unterstützen und in ihren Fraktionen dafür werben werden. 